\title{
Quotient-difference Algorithm: Application in Seismic Observation Results Processing
}

\author{
Maria Myasnikova \\ Penza State University, Penza, Russia
}

doi: https://doi.org/10.21467/abstracts.93.45

\begin{abstract}
The possibility of applying the method based on extremal filtering and its modification using the method of quotients and differences to process the results of seismic observations is considered. The data recorded by seismometers at stations around the world measure the movement caused by earthquakes, volcanic eruptions, and other seismic sources. Identification of the parameters of the seismic signal allows to highlight significant events, determine the estimated time of arrival of the primary wave and secondary wave, etc. Such parameters are automatically determined even on Internet resources containing open sources of geological and geophysical data [1].

Despite the fact that seismic stations are located at a regulated distance relative to the surrounding sources of natural technogenic noise [2], there are a number of tasks in which it is necessary to identify signals of weak seismic events observed against the background of natural seismic interference. For example, the need to obtain knowledges about the deformation processes in the upper part of the earth's crust, in areas where mining is carried out and blasting is carried out regularly [3]. The detection of certain seismic events (earthquakes of varying degrees of distance from the registration system, rockfall, drilling, helicopter landing, etc.) is based on the fact that the constantly observed seismic background and the signal, registrated during this type of seismic activity, have differences in power and frequency range. When any kind of such events occurs, the power of the recorded signal increases, and its spectrum shifts toward lower frequencies. The frequency analysis for dividing events into classes is most often based on the Fourier transform and filtering. However, this approach is not adaptive, since the Fourier transform has known drawbacks (computational complexity, spectrum blurring, etc.), and filtering is performed in a given frequency band. These drawbacks make us look for other ways to solve this problem. An example, the signal analysis based on extreme filtering $[4,5]$.

In the method of extreme filtering (EF), the alternating component (mode) and smoothed (not containing this component) are distinguished by the extrema of the signal; then the same actions are performed on the smoothed component until the smoothed component becomes a fashion. The mode parameters frequencies and, for example, power - are used to estimate the signal spectrum in the analysis section.

The EF is the least time-consumingmethodfor analysis in real time. However, the development of modern methods of digital processing allows us to return to the classics, but using other methods of spectral estimation. One of these methods is the Rutishhauser parametric analysis method - the algorithm of quotients and differences (QD-algorithm). As in the case of the application of parametric methods [6], it approximate signal as sum of the vibrational components of various frequencies, amplitudes, attenuation coefficients, and phases.

The determination of the poles and, accordingly, the frequencies of the components of the signal in this method is much less time-consuming than in parametric methods (Prony, Pisarenko, etc. [6]). This is due to the fact that instead of the solving of the high-order equation, the quotients and differences method solves
\end{abstract}

(C) 2020 Copyright held by the author(s). Published by AIJR Publisher in "Abstracts of The Second Eurasian RISK-2020 Conference and Symposium" April 12- 19, 2020, Tbilisi, Georgia. Jointly organized by AMIR Technical Services LLC, Georgian Technical University, Institute of Geography (Kazakhstan) and Russian Institute of Petroleum Geology and Geophysics.

AijR DOI: $10.21467 /$ abstracts.93 
The Second Eurasian RISK-2020 Conference and Symposium

equations of second and less order. Due to the nature of the algorithm (calculation of quotients), the method is sensitive to noise. Therefore, the method was modified for measurementtasks [7].

Fig.1, a shows the results of analysis of a seismic signal received from a seismic receiver during alternating events (riding car, group of running people) with a high-frequency seismic background. The upper graph is the values of the seismic signal in relative units; the second graph is the change of the mode frequency from site to site; the bottom graph is the change of the mode power from site to site. For example, the parameters of 3 high-frequency modes are shown. Figure 1, b shows the application of the method of quotients and differences for the same signal and the selection of its high-frequency component.
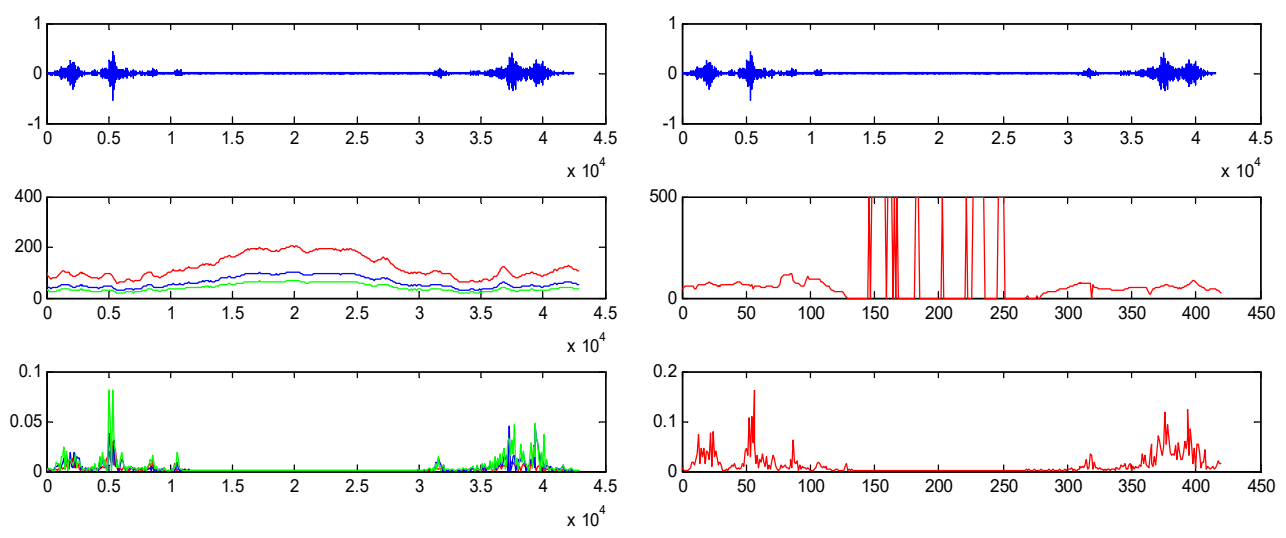

a

$\mathrm{b}$

Fig.1. Differentiaton of seismic signal components based on: $a$ - EF-method, b - quotients and differences method

The results show that any one diagnostic feature is sufficient to detect a change in the nature of the signal. Thus, it is enough to know about the change in mode frequencies to detect an event of a certain type. The abilities of using the quotients and difference algorithm for identifying events of different origin in seismic observation systems are shown.

\section{References}

1. https://www.iris.edu/app/station_monitor/

2. Krasovsky A.A. Digital signal processing in Zetlab for identification of seismic signal parameters -Moscow, Digital signal processing, No. 3/2010, pp. 70-76.

3. Varypaev A.V., Sanina I.A. Identification of signals of weak seismic events from records of a small aperture group when monitoring local seismicity of mine workings - Moscow, Dynamic processes in the geospheres, No. 10/2018, pp. 38-46.

4. Myasnikova N.V., M.P.Beresten, B.V.Tsypin, and M.G.Myasnikova. Express Analysis of Signals in Engineering Tasks. Moscow: FIZMATLIT, 2016.

5. Dudkin V.A., Myasnikova N.V., Mitrokhin M.A., Firsov M.S., Volskov A.A. A method for detecting moving objects by a seismic signal - Patent for invention RU 2365945 C1, 08.27.2009. Application No. 2008128036/28 of 07/09/2008.

6. Marpl S., Digital Spectral Analysis: With Applications, Prentice Hall, Englewood, Cliffs, NJ, 1987.

7. Bondarenko L.N., Dmitrienko A.G., Myasnikova M.G., Tsypin B.V. Method and device for approximating signals Patent for invention RU 2467385 G06F, 04.08.2011. Application No. 2011132897/08. 